\title{
MANEJO DE ÁGUAS SERVIDAS E A EXPERIÊNCIA DE MONITORAMENTO HIDROCLIMÁTICO EM AMBIENTE SEMIÁRIDO
}

\author{
Jémison Mattos dos Santos ${ }^{1}$ \\ Fabrício Oliveira Dias ${ }^{2}$ \\ Suílian Sampaio de Jesus ${ }^{3}$
}

\begin{abstract}
Resumo: A pesquisa foi desenvolvida sob uma perspectiva participativa, na comunidade rural de Itaetê, região da Chapada Diamantina-Ba. Na qual buscou-se analisar o manejo das águas servidas e a experiência do monitoramento hidroclimático. Alinhada a temática ambiental e educação no campo, em prol de melhores condições sanitárias e, ao mesmo tempo, associando a dinâmica climática, segurança alimentar e hídrica. Discute-se de maneira sucinta a necessidade do manejo racional dos recursos hídricos e o manejo ecológico da água, através de fundamentos teóricos-conceituais e oficinas visando à instalação/operação de uma unidade experimental de tratamento de efluentes domésticos (técnica zona de raízes), na Escola Família Agrícola (EFA). Além disso, objetivou-se promover à apreensão dos conteúdos trabalhados, de maneira satisfatória, integrando conhecimentos científicos com saberes locais, para aprofundar a reflexão sobre a dinâmica e os processos ambientais ocorrentes na EFA, ou seja, tecer o processo de popularização das ciências no semiárido baiano.
\end{abstract}

Palavras-chave: Manejo de Água, Monitoramento Hidroclimático, Leito de Raízes, Popularização das Ciências.

\section{WASTE WATER MANAGEMENT AND THE EXPERIENCE OF HYDROCLIMATIC MONITORING IN A SEMI-ARID ENVIRONMENT}

Abstract: The research was developed from a participatory perspective, in the rural community of Itaetê, Chapada Diamantina-Bahia region. In which we sought to analyze the management of wastewater and the experience of hydroclimatic monitoring. Aligned the environmental theme and education in the field, in favor of better sanitary conditions and, simultaneously, associating the climatic dynamics, food and water security. The need for rational management of water resources and ecological water management is briefly discussed, through theoretical-conceptual groundwork and workshops aiming at the installation/operation of an experimental unit for the treatment of domestic effluents (root zone technique), at an Agricultural Family School (EFA). In addition, the objective was to promote the understanding of the contents worked, in a satisfactory way, integrating scientific knowledge with local knowledge, to deepen the

\footnotetext{
${ }^{1}$ Professor Assistente da Universidade Estadual de Feira de Santana (UFS). Email: jemisons@uefs.br

${ }^{2}$ Bacharel em Geografia pela Universidade Estadual de Feira de Santana (UFS). Email: fabriciogeo29@ gmail.com

${ }^{3}$ Bacharel em Geografia pela Universidade Estadual de Feira de Santana (UFS). Email: ssj.uefs@gmail.com
} 
reflection on the dynamics and environmental processes occurring in the EFA, that is, to weave the process of popularization of sciences in the semi-arid region of Bahia.

Keywords: Water Management, Hydroclimatic Monitoring, Roots Zone, Popularization of Sciences.

\section{INTRODUÇÃO}

A região selecionada para execução do estudo está inserida no semiárido baiano e possui algumas peculiaridades (vegetação de caatinga, distribuição errática das chuvas, baixo nível tecnológico, educacional e saneamento precário em áreas rurais etc.) (VELOSO, 1992; IBGE, 2010, SANTOS, 2016; MENDONÇA \& DANNIOLIVEIRA, 2017). Por se tratar de estudo que envolve uma comunidade rural (sede de uma escola agrícola), é necessário destacar que o processo pensado para a "educação ambiental tem como propósito básico incorporar a cultura ambiental nas percepções, nos comportamentos e no imaginário das populações" (RODRIGUEZ \& DA SILVA, 2010, p. 139).

Por isso despertou-se o interesse no manejo dos recursos hídricos articulado a questão do saneamento local, visando popularizar o conhecimento científico e contribuir para melhoria das condições ambientais, através de treinamentos, interpretação e análise de dados climáticos, dos aspectos e impactos relacionados aos efluentes domésticos.

Saneamento é o conjunto de medidas que visa preservar ou modificar as condições do meio ambiente com a finalidade de prevenir doenças e promover a saúde, melhorar a qualidade de vida da população e à produtividade do indivíduo e facilitar a atividade econômica (TRATA BRASIL, 2020).

A falta de saneamento no Brasil é uma realidade antiga, de acordo com Pagliarini Jr et. al (2012); mesmo no âmbito das políticas públicas do Estado e, também, ratificada pela Constituição Federal na Lei ํo. $11.445 / 2007$, na qual consta que cerca de $48 \%$ da população brasileira não possui coleta de esgoto (SNIS, 2017). Para mitigar o problema do saneamento, que porventura afeta principalmente as pessoas mais pobres, o esgoto doméstico pode ser tratado utilizando técnicas diversas, utilizando métodos de baixo custo e contribuindo para o cuidado e manutenção da saúde de pessoas que vivem em comunidades rurais carentes (SPERLING, 1996; SALATTI, 2003; VAN KAICK, 2002; OLIJNYK, 2004).

A OMS (2018), publicou o livro "Guidelines on sanitation and health" que particulariza os problemas vivenciados no mundo em escala socioeconômica e ambiental. Tanto a OMS e outras instituições nacionais ligadas ao governo federal, a exemplo do Sistema Nacional de Informação sobre Saneamento (2017), Ministério do Meio Ambiente (2019), Instituto Trata Brasil (2020), Fundação Oswaldo Cruz (2019), Ministério da Saúde (2020), buscam através de políticas públicas e parcerias públicoprivadas mapear o problema do saneamento e organizar ações para levar serviços sanitários para a população menos favorecida.

É assustador, que na modernidade, vivenciado o período técnico-científicoinformacional "892 milhões de pessoas ainda realizam a defecação a céu aberto" (SANTOS, 2002; UNESCO, 2019).

"No mundo os ambientes poluídos matam 1,7 milhões de crianças" (OMS, 2017). "Em alguns dos países menos desenvolvidos, $49 \%$ das escolas não têm acesso à água e 53\% não têm acesso a instalações sanitárias” (WHO, 2017). Já no Brasil, 7 em cada 10 (pessoas) vivem sem saneamento adequado (UNICEF, 2015). 
Portanto, por meio dos dados e informações analisadas foi possível compreender com mais clareza aspectos fundamentais das condições sanitárias no Mundo, Brasil, Nordeste e na EFA. Merece destaque, de início, a elaboração do diagnóstico ambiental participativo, uma vez que, percebeu-se a carência de informações socioambientais. Além disso, as áreas rurais são pouco assistidas pelo Estado, o que contribui para práticas de descarte e despejo de lixo e esgoto no ambiente, "[...] na zona rural, $59,6 \%$ da população queima ou enterra seus resíduos, apenas $28,8 \%$ dispõem da coleta, $11 \%$ jogam em terrenos baldios e $0,1 \%$ descartam à beira de rios e lagos; um cenário alarmante" (IBGE, 2010 apud NOGUEIRA \& IMPERADOR, 2016, p.208).

Logo, objetiva-se analisar o manejo das águas servidas e a experiência do monitoramento hidroclimático na EFA, com intuito de promover a melhoria das condições ambientais e de vida na comunidade, bem como difundir o conhecimento sobre recursos hídricos e a conservação ambiental, por meio de práticas sustentáveis, comprometidas com as gerações futuras e o planejamento (no médio e longo prazo) das atividades socioprodutivas.

Além disso, sensibilizar e capacitar a comunidade local, demonstrar a importância do conhecimento científico, do uso e aplicação do conjunto de instrumentos de precisão (p.ex.: estação meteorológica digital, Modelo NEXUS35.1075), que possibilitam avaliar as características climáticas locais.

A pesquisa em questão, caracteriza-se na ampliação, integração e popularização do conhecimento científico, impactando positivamente às pequenas comunidades rurais de Itaetê. Este trabalho é parte de um projeto maior denominado "ÁGUA DÁ VIDA: O RIO QUE VAI, TRAZ A VIDA TAMBÉM", desenvolvido no Laboratório de Estudo da Dinâmica e Gestão de Ambiente Tropical (GEOTRÓPICOS), pelo grupo de pesquisa GEOLANDS (Ciência, Tecnologia em Evolução da Paisagem, Solos e Planejamento), ambos da Universidade Estadual de Feira de Santana - UEFS.

\section{MATERIAIS E MÉTODOS}

Para definição dos métodos de abordagem e procedimentos foram trabalhados alguns pesquisadores que atuam na engenharia sanitária, geografia e áreas afins das ciências do ambiente, a exemplo de Salatti, (2003), Van Kaick (2002). E outros autores clássicos e contemporâneos que tratam dos recursos hídricos e semiárido, tais como, Maia, (1997), Rebouças (2006), Ribeiro (2008), Santos, (2008 e 2016), todos fundamentais para consolidar o referencial teórico-conceitual e arcabouço metodológico deste estudo.

Estrategicamente, adotou-se no escopo deste estudo a Pedagogia da Alternância, pois esta busca valorizar o que se faz no ambiente familiar associando aos conhecimentos da educação do campo.

Na Pedagogia da Alternância, o saber prático obtido junto à família, na execução das tarefas e a teoria, obtida na escola durante a troca de experiências e absorção dos conteúdos ensinados, se fundem. Assim, podem auxiliar a aprofundar a compreensão do que ocorre no dia a dia, na família e escola, e onde o conhecimento emerge, se amplia e se consolida, facilitando ao jovem alternar e valorizar aquilo que ele faz e sabe. É na vinculação do conhecimento escolar com a ambiência familiar que o jovem reflete sobre seu meio e elabora marcos de referência (CALIARI et al, 2002 p.18). 
Iniciou-se o trabalho com a elaboração consistente do referencial teóricoconceitual, a partir do acervo encontrado na Biblioteca Central Julieta Carteado (BCJC-UEFS); no laboratório GEOTRÓPICOS-UEFS; como também em outros sites institucionais (p.ex.: ANA, EMBRAPA, INPE, IBGE).

Na sequência tem-se a estruturação e, posterior, realização de uma oficina com enfoques voltados para a gestão integrada dos recursos hídricos, manejo ecológico da água, problemática da poluição dos corpos d'água e, exemplos de sistemas de tratamentos de efluentes domésticos, que podem ser aplicados em comunidades rurais. Foi dado ênfase à importância socioambiental do uso de tecnologias de baixo custo (p.ex.: zona de raízes).

Após a supracitada atividade foi realizada uma fala embasada na lei 9.433 de 8 de janeiro de 1977 (Política Nacional de Recursos Hídricos), para sensibilizar e tratar dos deveres e direitos deste bem público e da urgência da preservação ambiental das áreas produtoras de água.

Para tal momento, fez-se a distribuição de uma cartilha educativa sobre recursos hídricos, desenvolvida pela equipe, com conteúdo ilustrado e autoexplicativo, para que os participantes possam aprender de maneira simples/direta.

Por fim, desenvolveu-se a atividade prática, nomeada "DIA DO CAMPO: A COMUNIDADE VAI AO RIO":

- No primeiro momento, foram realizadas medições no canal do rio Una e do rio Invernado, a exemplo da largura, do comprimento, profundidade, temperatura e velocidade da água para obter a seção transversal e a vazão, usando métodos diretos e indiretos (convencionais e não convencionais). Para a etapa de medição das velocidades médias nas verticais em vários pontos (pelo método detalhado), adotouse a tabela apresentada por Santos et al (2001).

As distâncias utilizadas entres as verticais para os rios avaliados, durante o trabalho de campo, respectivamente, foram definidas em relação à Largura do canal $(m)$ : a) largura do canal $(<3,0)$ a distâncias entres as verticais $(m)$ é igual a $(0,30)$; b) largura do canal entre $(3,0$ à 6,0$)$ a distâncias entres as verticais $(m)$ é igual a $(0,50)$; c) largura do canal entre $(6,0$ à 15,0$)$ a distâncias entres as verticais $(\mathrm{m})$ é igual a $(1,00)$; d) largura do canal entre $(15,0$ à 30,0$)$ a distâncias entres as verticais $(m)$ é igual a $(2,00)$;

- O segundo momento, deu-se por meio das práticas de observações da dinâmica fluvial às margens dos rios e algumas reflexões sobre as alterações ambientais, causadas pelo conjunto de atividades socioeconômicas. Além da coleta de sedimentos em suspensão e de fundo do rio em pontos previamente selecionados.

Para execução destes procedimentos foram utilizados alguns equipamentos de precisão, tais como: micro molinete hidrométrico, GPS de navegação (marca Garmin GPS map 76Cx), bússola tipo Silva, termo anemômetro digital (Incoterm, modelo TAN 100), dentre outros.

Finalizou-se a etapa através de medições de algumas variáveis climáticas na EFA, definidas anteriormente, tais como: temperatura, direção e velocidade do vento. Para a etapa acima mencionada foram apresentados conteúdos técnicos e informações aos participantes sobre uso da estação meteorológica digital (Nexus Modelo 35.1075). Informando-os sobre os sensores remotos que coleta e transmite dados meteorológicos, tais como: temperatura externa, umidade, velocidade e direção do vento, quantidade e intensidade da chuva, dentre outros.

Dessa forma, buscou-se conscientizar os estudantes, professores e gestores sobre a importância do conhecimento da realidade ambiental e do tratamento de efluentes domésticos na EFA, para auxiliar a conservação dos recursos hídricos, na 
prevenção de doenças advindas do esgoto doméstico e evitar a poluição do ambiente.

\title{
RESULTADOS E DISCUSSÃO
}

O acesso à água potável para o consumo humano e ao saneamento básico vai além da necessidade da população, pois se constitui um direito assegurado por lei. $E$ um dos princípios da Lei no. 11.445/2007 é a universalização dos serviços de saneamento básico, para que todos tenham acesso ao abastecimento de água de qualidade e em quantidades suficientes às suas necessidades, à coleta e tratamento de esgoto (FUNASA, 2019; DIÁRIO DAS LEIS, 2019; TRATA BRASIL, 2012). É advinda da utilização da água a produção de mercadorias tanto na área industrial quanto na agricultura.

Diante de suma importância da água são requeridos estudos que possam assegurar formas mais satisfatórias de gerenciamento do uso e o planejamento que promova a cultura de cuidado, de poupança, ou seja, hábitos capazes de contribuir para evitar o desperdício e a poluição. Assim, as inúmeras situações danosas ocasionadas pelo uso inadequado da água geram/intensificam a escassez hídrica, que atinge a presente e poderão afetar negativamente às futuras gerações. Diante disso ressalta-se o importante valor dado à água, como referenciado por Rebouças (2006):

\begin{abstract}
A água é um elemento essencial à vida no planeta Terra, em especial ao homem, no que tange ao abastecimento para consumo humano, ao desenvolvimento das atividades industriais e agrícolas e ainda à vida dos animais e vegetais. Contudo, é um recurso vulnerável às modificações no ambiente de origem, por onde percolam ou onde são armazenadas, devido aos diferentes usos e ocupações pelas ações humanas (REBOUÇAS, 2006, p.01).
\end{abstract}

Quando o uso desse recurso natural é efetivado de modo irracional advêm inúmeros prejuízos, no âmbito social e econômico. Pois, na contemporaneidade a fome de terra e a sede inigualável do capital, cada vez mais põem em risco os sistemas ambientais, os recursos hídricos, tanto no contexto local quanto global.

Dentro desse cenário de escassez e poluição anunciada, a reutilização da água é uma das possibilidades concretas de reversão do quadro crescente de pressões e implicações ambientais negativas, que paulatinamente comprometem à disponibilidade do acesso à água potável em nosso país.

Segundo o Instituto Trata Brasil (2019), "quase 100 milhões $(53,15 \%)$ de pessoas não têm acesso à coleta de esgoto e em 2017 tiveram mais de 258 mil internações por doenças de veiculação hídrica".

A água não possui capacidade de renovação (recurso natural que depende de eficientes modos de uso). É por meio dela que conseguimos produzir ampla variedade de mercadorias, o que significa que somos altamente dependentes da água. Ao mesmo tempo é crucial contribuir para a conservação e preservação, em prol de condições que nos permita uma vida saudável e sem a ocorrência de conflitos nos longos períodos de escassez, pois para Ribeiro (2008) como:

Água é fonte de conflito porque sua distribuição natural não corresponde à sua distribuição política. Em alguns países os recursos hídricos são mais que suficientes para abastecer as necessidades de seu povo. Mas eles são raros em outros. Como o estilo de vida hegemônico está baseado no consumo incessante de mercadorias, o 
uso da água para a produção industrial tende a aumentar, o que pode desencadear novos conflitos pelo seu acesso (RIBEIRO, 2008 p.17).

Diante das inúmeras reflexões é possível imputar a responsabilidade da sociedade, em geral, principalmente, aqueles setores produtivos que consomem volumes elevados de água (p.ex.: a agricultura e a indústria) em relação ao uso sustentável, bem como promover discussões e ações norteadoras para o alcance dos benefícios ecológicos e socioambientais, como bem enfatizada na lei 9.433 de 8 de janeiro de 1977.

A temática dos recursos hídricos é considerada estratégica, pois alguns membros da comunidade são ribeirinhos, que estão inseridos na bacia hidrográfica do Rio Una, ou seja, é deste canal fluvial que se retira parte do sustento das famílias. Portanto, a conservação e preservação ambiental dos rios contribui decisivamente com a segurança alimentar da população local.

Dada a importância dos rios, as atividades de campo (Figura 01), foram pensadas e realizadas no sistema fluvial próximo a EFA, em conjunto com estudantes e professores, que compartilharam conhecimentos e experiências locais de imensurável valor. Tornando possível a integração entre o conhecimento popular e o acadêmico.

Ressalta-se neste processo a importância do conhecimento popular. Além disso, é necessário estar atento às diversas práticas sustentáveis desenvolvidas pela comunidade, não somente aos aspectos ambientais negativos, principalmente, aquelas que auxiliam na manutenção do equilíbrio entre as condições ambientais e as atividades socioprodutivas da EFA (p.ex.: uso de adubação orgânica, priorização da aplicação de pesticidas e herbicidas naturais, não utilização de queimadas, não retirada da mata ciliar).

Figura 1. Oficina: importância da conservação dos recursos hídricos, manejo da

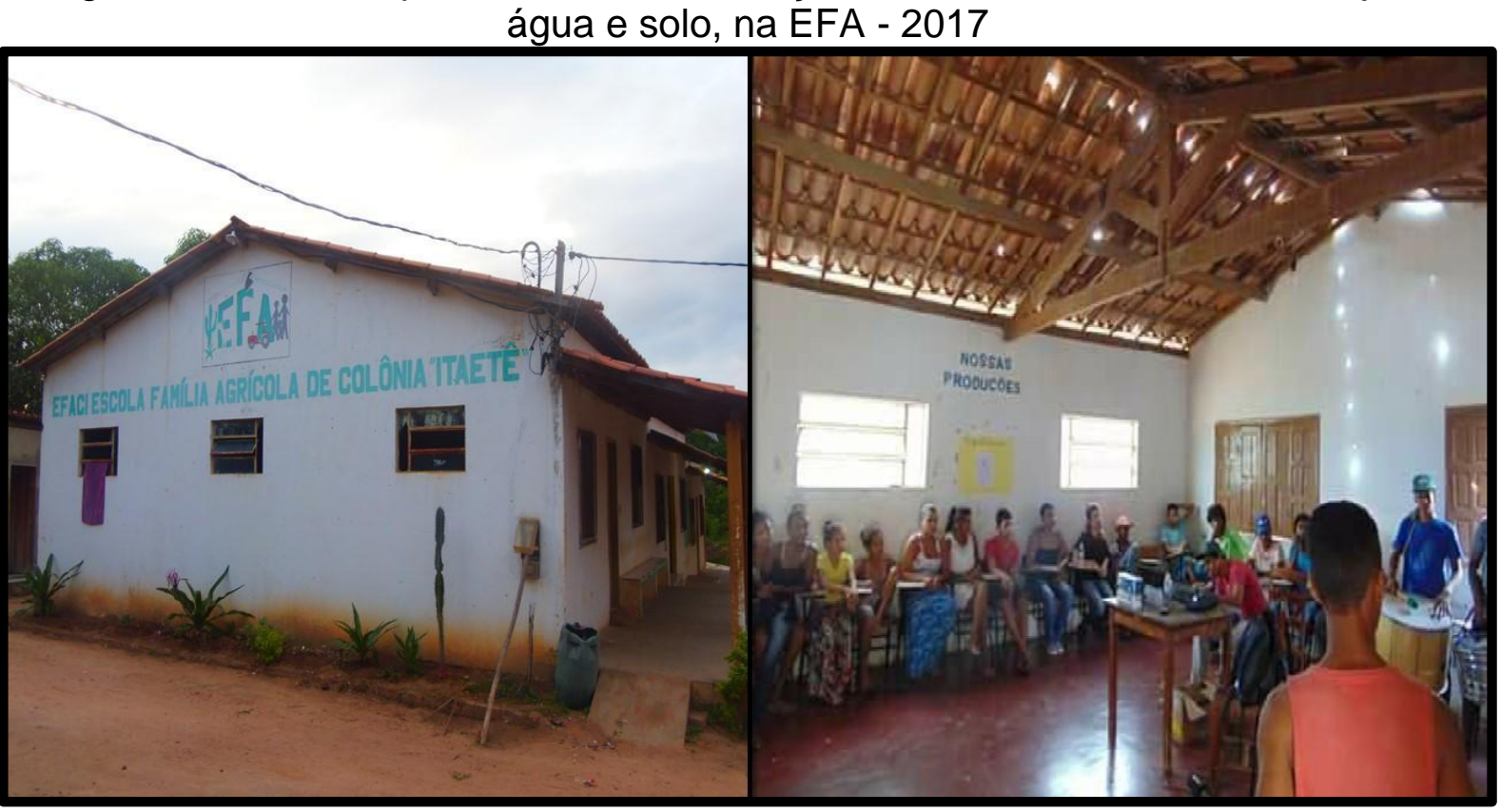

Fonte: Arquivo dos autores, 2017

Em relação ao tratamento de águas servidas em pequenas comunidades rurais, este se constitui questão crucial para o desenvolvimento do saneamento básico rural 
no nosso país e Nordeste. Pois, entende-se que o lançamento indiscriminado de águas residuais domésticas no Brasil e no mundo é um dos maiores problemas ambientais e de saúde pública (BRASIL, 2011 e 2019; UNICEF, 2017 e 2019; OMS, 2017; UN-WATER, 2019).

O acesso universal ao saneamento adequado é uma necessidade fundamental e um direito humano. Garantir o acesso de todos ajudaria bastante a reduzir doenças e mortes, principalmente entre as crianças. Desde 2000, 2,1 bilhões de pessoas obtiveram acesso ao saneamento básico, como descarga de vasos sanitários ou latrina com uma laje que não é compartilhada com outras famílias. Em 2017, 2 bilhões de pessoas ainda carecem de um serviço de saneamento básico e, entre elas, quase 673 milhões de pessoas ainda praticavam defecação a céu aberto. Os dados revelam disparidades pronunciadas, com os mais pobres e os que vivem em áreas rurais com menor probabilidade de usar um serviço básico (UNICEF, 2019, p.1).

O que mais chama a atenção na série histórica dos dados relativos aos tipos de escoadouros de esgotos nos domicílios rurais brasileiros é a persistência das fossas rudimentares, cuja situação é praticamente inalterada entre 1991 e 2010. Há uma redução no percentual de domicílios com fossa séptica entre 1991 e 2000, de 26\% para 15\%, e uma estagnação em torno deste último patamar em 2010. Torna-se evidente que tal mudança esteve relacionada ao aumento de domicílios com esgotos dispostos em vala, rio, lago ou mar, e que aumentaram a sua participação relativa no ano de 1991 , de $12 \%$, para $16 \%$, em 2000 , valor que se manteve constante em 2010, na Figura 02 (FUNASA, 2019).

A carência sanitária coloca em risco a saúde das pessoas que não tem acesso a água potável, uma vez que as águas são utilizadas in natura dos rios "[...] a presença de coliformes fecais na água indica sempre, a presença de esgotos, e esta, por sua vez, significa a possibilidade da presença de patógenos [...]" (BRANCO, 1989, p. 44).

Figura 2. Evolução dos tipos de escoadouros e esgotos nos domicílios rurais

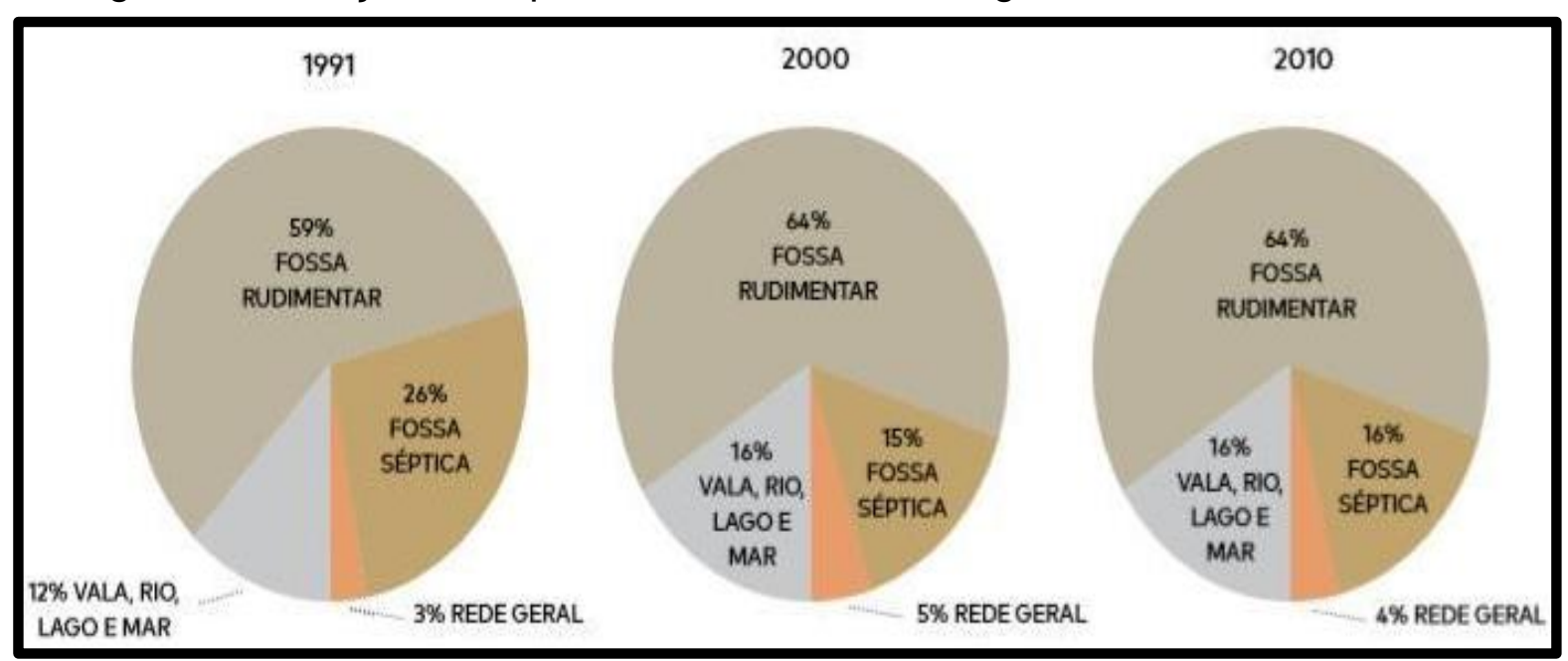

brasileiros

Fonte: IBGE (1991, 2002, 2011- Censos demográficos de 1991, 2001, 2010, dados da amostra (Considerando a delimitação de rural do IBGE). 
Mediante a situação observada e vivida na EFA, é uma prática diária, as pessoas da comunidade utilizarem água diretamente dos rios, a partir de sistemas de bombeamento ou coleta direta através de carros pipas. A água canalizada ou coletada chega às residências, onde são consumidas nas tarefas cotidianas (p.ex.: beber, cozinhar, serviços de higiene doméstica, irrigar culturas).

Entre os benefícios advindos da adoção do descarte consciente das águas servidas, está estritamente ligado às questões de saúde da comunidade. O manejo dos recursos hídricos se faz necessário pela elevada contaminação dos corpos hídricos, que acontecem quando não há manipulação correta de efluentes domésticos, por exemplo, na EFA, o que é preocupante.

Diante do cenário exposto, vê-se a necessidade de manter o equilíbrio de todo o ambiente e não apenas para atender as necessidades dos agentes locais (JIA et al, 2013).

Segundo Baptista et al (2005) dada a significativa importância para o manejo adequado dos recursos hídricos e das águas servidas, visa-se de maneira higiênica e saudável implementar um sistema de tratamento de efluentes doméstico através do leito de raízes, que transfira para um lugar tecnicamente avaliado, a captação dessas águas servidas, no propósito de não contaminação direta ou indireta dos recursos hídricos (nascentes, lençol freático, rios, etc.) existentes na localidade.

A técnica leito de raízes é entendida como uma das melhores alternativas (sustentáveis) para o saneamento rural. Pois são ditos sistemas naturais, que se baseiam na capacidade de ciclagem de elementos contidos na água residuária sem fornecimento de qualquer fonte de energia para acelerar os processos biogeoquímicos, os quais ocorrem de forma espontânea (OLIJNYK et al.,2007).

Baseado em Kaick (2014), na figura 03, observa-se um perfil estrutural de estação de tratamento de esgoto doméstico sustentável.

Figura 3. Estação de tratamento de efluentes domésticos a partir do sistema zona de raízes (ETEDZR)

Figura 3 - Perfil estrutural da Estaçăo de Tratamento de Esgoto (ETE)

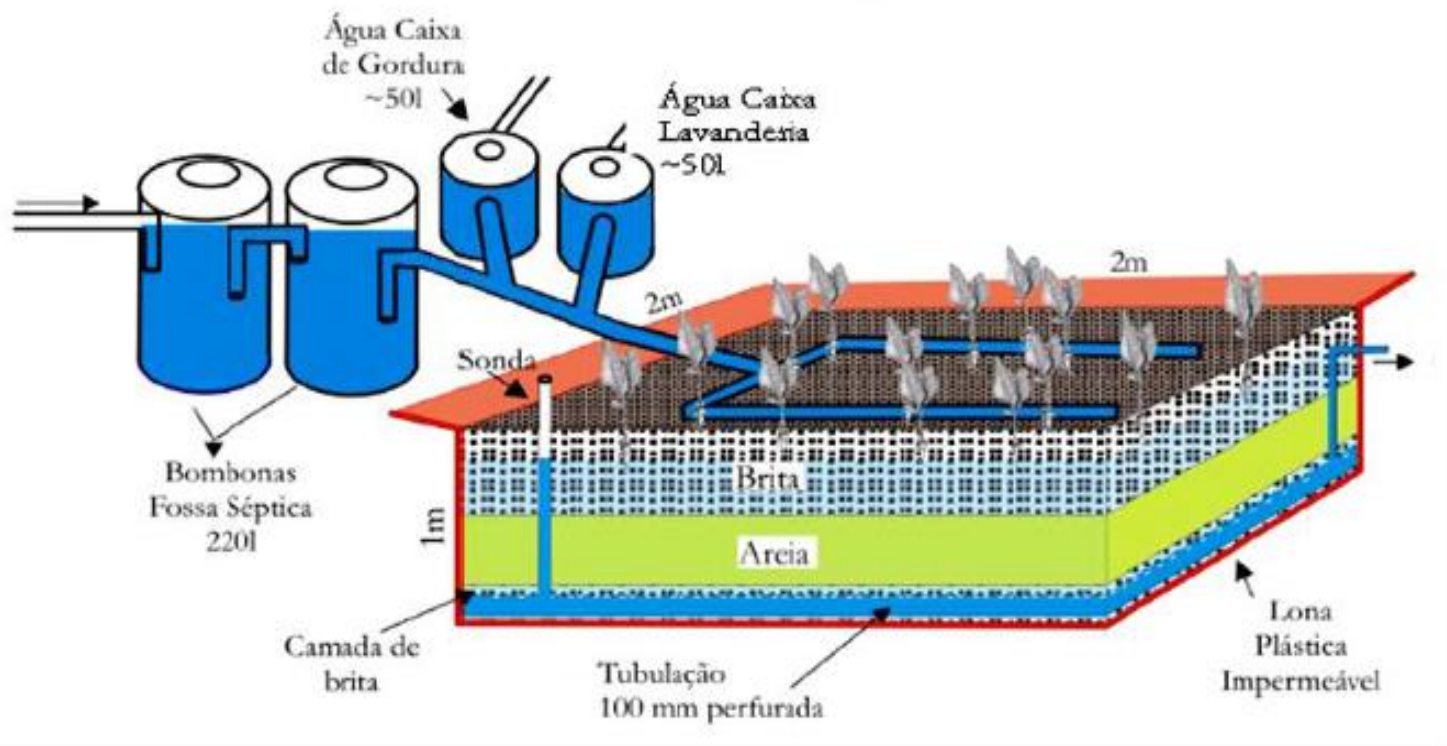

Fonte: Parolin, Crispim e Kaick (2014) 
Já nas figuras 4 e 5, é possível entender passo a passo como é efetuado processo de construção e finalização de uma ETEDZR.

Figura 4. Construção: passo a passo de uma ETEDZR

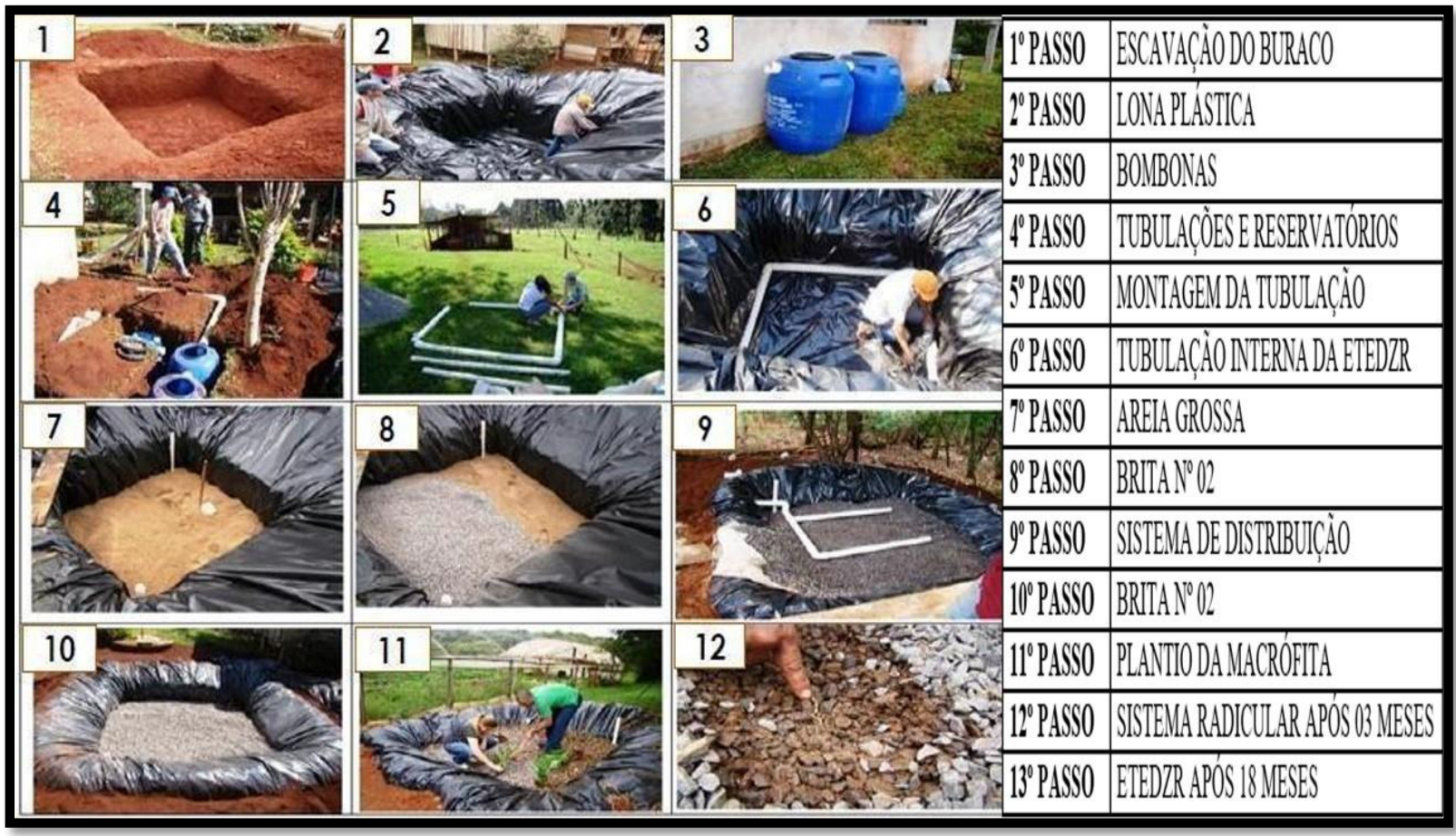

Fonte: Parolin, Crispim e Kaick (2014)

Figura 5. Estação de tratamento de efluentes domésticos por zona de raízes finalizada

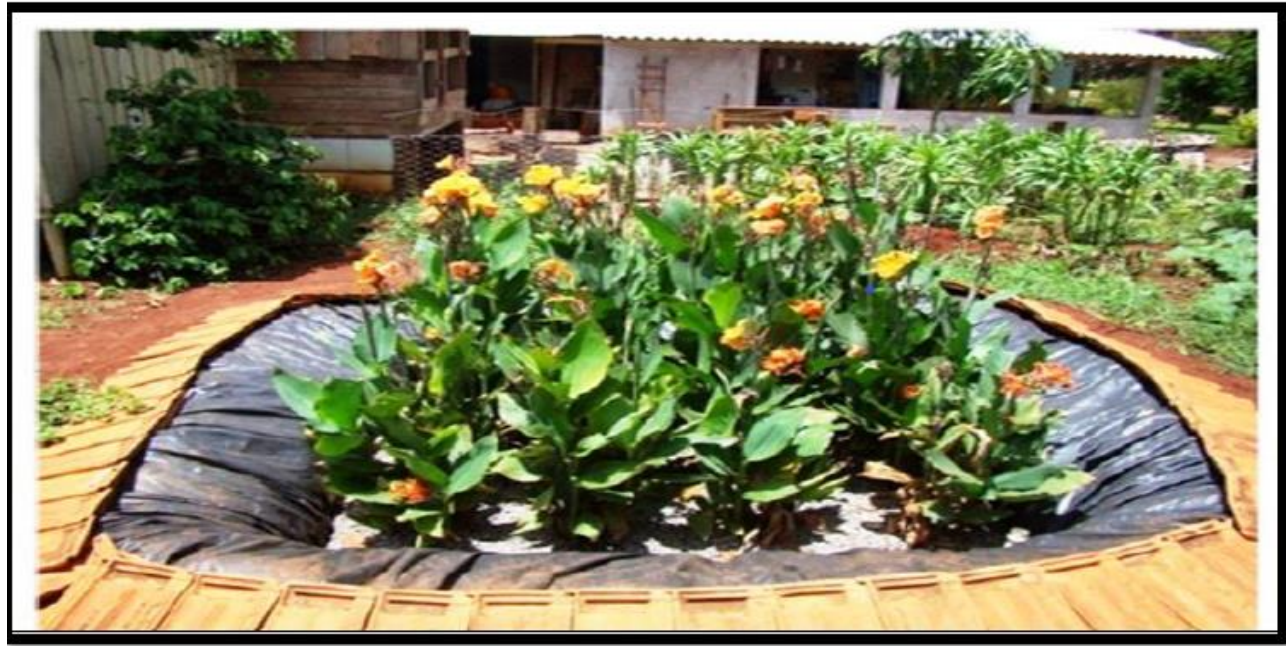

Fonte: Parolin, Crispim e Kaick (2014)

Esse sistema se destaca pela sua eficiência no processo de degradação da matéria orgânica e ainda contribui na remoção de nutrientes, como fósforo e nitrogênio. $\mathrm{Na}$ perspectiva de complementar o conceito anterior observam-se inúmeras formas de uso da técnica leitos de raízes, como afirma Salatti (2003): 
Os sistemas zonas de raízes, construídos, podem ser utilizados como: tratamento integral do esgoto doméstico; tratamento secundário e terciário de esgoto; tratamento de efluentes agrícolas; barreiras de retenção; recuperação de áreas alagadas; entre outros (SALATTI, 2003, p.39).

O sistema de zona de raízes é uma técnica de baixo custo e simples manuseio que pode melhorar a vida das pessoas, principalmente, no espaço rural. Para Salatti (2003) são diversas utilidades encontradas no tratamento do esgoto doméstico favorecendo sempre a proteção do ambiente.

A necessidade de instalar e manusear uma ETEDZR na EFA ficou evidente quando foi realizado o diagnóstico ambiental, em 2018, pela equipe do GEOLANDS. A partir daí refletiu-se sobre os aspectos socioeconômicos e alterações físico-naturais, - local mais adequado para construir a estação e devolver água despoluída, na perspectiva futura de efetuar o reuso dos efluentes nas atividades agrícolas.

Nesse movimento foram evidenciados os principais problemas que se referem à carência financeira, a ausência de manejo do solo e água, a ocorrência de processos acelerados (erosão em sulcos e ravinamento), bem como despejo de águas servidas numa fossa rudimentar, descoberta e com canalização danificada; que claramente não apresenta estrutura física adequada para receber os efluentes domésticos (Figura 06).

"A fossa negra é um tipo primitivo de saneamento, proibida em diversos municípios e Estados brasileiros devido aos riscos ao meio ambiente que elas representam, sendo considerada um crime ambiental" (ECOCASA, 2016).

Nas comunidades onde os participantes da EFA residem, foi colocado que "os despejos dos esgotos domésticos também são realizados de modo inapropriado" (p.ex.: fossas rudimentares ou por escoamento superficial afetando negativamente $o$ ambiente e a saúde humana).

Figura 6. Problemas de erosão dos solos, poluição do solo e das águas, infraestrutura física e manutenção precária da fossa rudimentar na EFA - 2018

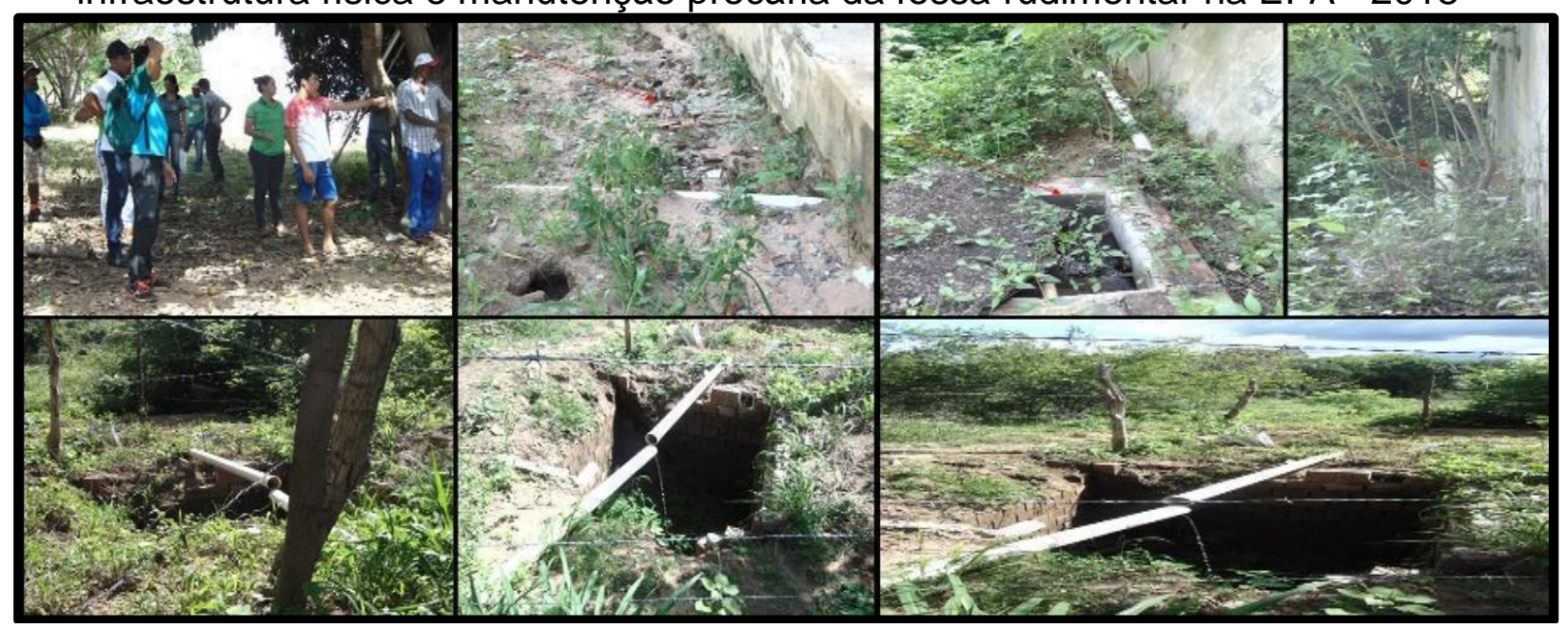

Fonte: Arquivo dos autores, 2018

A Organização Mundial da Saúde (OMS), no relatório "herdando um mundo sustentável: o atlas da saúde e do ambiente infantil", alertou que a poluição mata 1,7 milhão de crianças todos os anos no mundo. São mais de 3 mortes por segundo. Complementa em relação a poluição e ao saneamento que: 
Mais de $25 \%$ dos óbitos de crianças com menos de cinco anos têm como causa ambientes poluídos, entre eles estão a poluição externa e a interna, neste caso, o fogão à lenha é um exemplo clássico. Além deles estão o fumo passivo, água contaminada, falta de saneamento básico e higiene inadequada. Todos os anos, (...) pouco mais de 360 mil perdem a vida por causa da diarreia (OMS, 2017).

Constatou-se na EFA que a referida fossa rudimentar não se encontrava vedada adequadamente, em alguns trechos a tubulação estava rompida e o esgoto corre à céu aberto, ou seja, verificaram-se tubulações deterioradas (ressecadas e com pequenos buracos) resultando em vazamentos.

O perigo do manejo indevido desta fossa rudimentar está associado à proliferação de doenças, a exemplo, da Dengue, Chikungunya, Zika vírus, todas elas são originárias do mosquito Aedes Aegypti (mesmo em fossas rudimentares ou cinzas é de fundamental importância cobrir e vedar adequadamente). O lugar em questão possibilita a proliferação de ratos, baratas, dentre outros animais nocivos aos seres humanos.

Ao consultar o estudo que aborda a influência de fossas negras na contaminação de poços subterrâneos (...) tem-se "aproximadamente 50 tipos de infecções que podem ser transmitidas pelas excretas humanas. Epidemias como febre tifoide, cólera, disenteria e inúmeras doenças verminosas são transmitidas pela disposição inadequada dos esgotos" (SOUZA et. al apud ANA, 2005).

Chama-se à atenção ao risco potencial de queda no interior de fossas, principalmente, crianças e jovens. Pois, foi observado que a fossa rudimentar instalada na EFA está localizada bem próxima de algumas salas de aulas.

Notou-se também que as condições de infraestrutura dos espaços interiores e exteriores desta escola encontram-se bastantes precárias, pois a cozinha, refeitório, banheiros e a cobertura das salas de aulas necessitam de reformas estruturais e adequação dos telhados para, por exemplo, servir como área de captação de água de chuva.

O documento do Fundo das Nações Unidas para a Infância (UNICEF), "intitulado água e saneamento nas escolas do semiárido", reforça nosso estudo ao exatificar que existem:

Mais de 3 mil escolas do semiárido sem água e de mais de 1.500 sem esgoto. Também espelha como são instituições de ensino onde faltam cozinhas, refeitórios, depósitos para os alimentos e banheiros adequados. Esses e outros itens, como piso e telhados cobertos, fazem a diferença. Eles colaboram para um ambiente limpo, onde as crianças e os adolescentes podem aprender com higiene, saúde e segurança (UNICEF, 2017, p.8).

Esse rol de problemas evidenciados seguramente ocasiona alterações negativas de ordem sanitária e ambiental, podendo gerar efeitos indesejáveis na saúde da comunidade, poluir o solo e os recursos de água doce (os rios e água subterrânea).

A problemática constatada na EFA ilustra a realidade de uma parte do Brasil, em relação ao saneamento rural precário ou inexistente, principalmente nas regiões menos desenvolvidas, como é o caso da região nordeste e o estado da Bahia. Agravase a situação, ao constatar que o município de Itaetê não possui Política de Saneamento Básico, conforme a Lei 11.445/2007. 
Deste modo, os aspectos e impactos associados à poluição e/ou contaminação das águas são questões muito importantes, que devem ser analisadas, no contexto da região semiárida, principalmente em pequenas comunidades rurais, a exemplo da EFA.

Ao consultar experiências estrangeiras relacionadas ao tratamento de águas servidas (wastewater), a exemplo do departamento de qualidade ambiental de IDAHO (USA), apreende-se que:

A melhor maneira de reduzir o desperdício e outras poluições é evitar produzi-las em primeiro lugar. A prevenção da poluição (...) é qualquer atividade, incluindo o uso de materiais, processos ou práticas, que reduz ou elimina a criação de contaminantes ou resíduos na fonte. Em vez de tentar gerenciar resíduos ou contaminantes por meio de métodos de tratamento ou descarte, (...) evitar a geração inicial ou reduzir a toxicidade de resíduos e contaminantes, como resíduos perigosos, poluentes do ar, resíduos sólidos, esgoto, etc. (...) qualquer atividade que reduz a toxicidade dos materiais adquiridos ou 0 consumo de recursos como matérias-primas, água, energia ou combustível. Ao empregar práticas de prevenção da poluição, as partes interessadas podem melhorar a produtividade, economizar dinheiro, melhorar a segurança no local de trabalho, reduzir a responsabilidade e conservar os recursos naturais (IDAHO, 2019).

Grande parte desses problemas do semiárido nordestino é oriunda de más gestões da esfera pública, aliado aos extensos períodos de escassez de chuva e a ineficiente ou ausentes processo de planejamento dos recursos hídricos, forjando o cenário perfeito para ocorrência de prejuízos e/ou danos ambientais que afetam as comunidades rurais mais vulneráveis. Ao conceituar a nordeste brasileiro e a região semiárida Duarte (2001) e Santos (2008), respectivamente, diz que:

O Nordeste brasileiro é caracterizado por ser uma região com alta variabilidade climática intra-sazonal e interanual na qual os efeitos climáticos sobre os recursos hídricos são fatores que influenciam decisivamente no cotidiano das comunidades locais. A maioria da população enfrenta grave escassez de água e alimentos, repercutindo-se severamente sobre a saúde das populações, esboçando um cenário de aumento da mortalidade infantil e de restrições econômicas, que paulatinamente reproduzem condições precárias de sobrevivência das comunidades mais carentes.

A zona semiárida do Nordeste brasileiro caracteriza-se por ter uma das maiores densidades demográficas entre as regiões do planeta que apresentam características ambientais semelhantes. Tendo a área calculada em aproximadamente $882.000 \mathrm{~km}^{2}$, o semiárido nordestino abriga cerca de 18 milhões de habitantes e tem uma densidade demográfica elevada, em torno de $20 \mathrm{hab} . / \mathrm{km}^{2}$ (...) (DUARTE, 2001, p.15).

Em virtude do que foi mencionado anteriormente, se justifica a urgência de implementação da ETEDZR na EFA, bem como de apoio financeiro e técnico por parte do poder público estadual e municipal, destacadamente, por estar localizada em ambiente rural semiárido, e se tratar de uma região que comprovadamente possui déficit de saneamento básico rural. 
A exemplo da EFA construir uma estação para tratamento de efluentes domésticos servirá para que os corpos hídricos não sejam poluídos. Para tal fim, recomenda-se que os efluentes de qualquer fonte poluidora somente poderão ser lançados direto ou indiretamente nos corpos de água, após o devido tratamento.

Por meio desta pesquisa foram produzidas informações e difundidos conhecimentos técnicos, orientados para a proteção e conservação do ambiente em pequenas comunidades rurais. Nessa perspectiva, a universidade cumpre satisfatoriamente o papel primordial de contribuir com o desenvolvimento do país, assim como segue se aprimorando com a troca de saberes.

Por fim, destaca-se a necessidade de divulgação de 02 importantes documentos: i) "Informe sobre la salud en el mundo 2013: investigaciones para una cobertura sanitária universal'. Estudo importante pois revela tendências sobre a saúde mundial, acessibilidade aos serviços de saúde, pesquisa, dentre outros temas voltados para alcançar o saneamento básico universal, elaborado pela OMS; ii) Programa Nacional de Saneamento Rural, trabalho que enfoca fundamentalmente sobre aspectos do saneamento básico, da saúde ambiental e o saneamento rural, elaborado pela FUNASA em 2019.

\section{CONSIDERAÇÕES FINAIS}

A EFA apresenta sérios problemas relacionados às condições sanitárias precárias e ao manejo inexistente das águas servidas. Constata-se a total ausência de saneamento básico.

Quanto ao monitoramento hidroclimático local, confirma-se a necessidade premente de manutenção deste, pois permitirá que a comunidade compreenda o regime das chuvas e sua relação com a bacia do UNA, para que possa atuar de forma planejada no desenvolvimento das práticas agrícolas e no uso sustentável da água para consumo e produção.

A pesquisa também contribuiu para que os participantes, em geral, percebessem na prática que se o esgoto não é tratado adequadamente poderá poluir, contaminar o solo, os corpos hídricos (rios, lençóis freáticos) e provocar diversos tipos de doenças.

Portanto, devido ao conjunto de especificidades e benesses levantadas, afirmase que a instalação de uma ETEDZR, será de grande relevância, pois ocasionará melhorias ambientais e estéticas, por meio da aplicação de uma técnica de baixo custo financeiro (leito de raízes), baixo consumo de energia e manutenção, utilizando plantas adaptadas ao clima semiárido. Tecnologia sustentável que após apreendida pode ser replicada, com apoio da população em outros espaços rurais de Itaetê

É possível afirmar que, através do conjunto de atividades realizadas foi possível avaliar o maior interesse e participação comunitária, ou seja, efetivou-se o processo de popularização do conhecimento técnico-científico, com a finalidade de assegurar a valorização e a conservação dos recursos hídricos. Possivelmente, este trabalho repercutirá positivamente nas áreas rurais de Itaetê.

\section{REFERÊNCIAS BIBLIOGRÁFICAS}

BAPTISTA, M.; Nascimento, N.; Barraud, S. Técnicas Compensatórias em Drenagem Urbana. Porto Alegre: ABRH, 2005. 
BRANCO, Samuel Murgel. Água: origem, uso e preservação. Moderna, 1989.

BRASIL. Ministério da Saúde. Fundação Nacional de Saúde. Programa Nacional de Saneamento Rural / Ministério da Saúde, Fundação Nacional de Saúde. Brasília: Funasa, 2019. $260 \mathrm{p}$.

Agência Nacional de Águas (ANA). Disponível em: htpp://www 2.ana.gov.br /Páginas/imprenas/noticia.aspx?id_noticia=12525. Acesso em 20 de fevereiro de 2017.

Instituto Brasileiro de Geografia e Estatística - IBGE. Saneamento Básico:

Pesquisa Nacional de Saneamento Básico. 2019. Disponível em: https://ces.ibge.gov.br/base-de-dados/metadados/mte/200-comite-de-estatisticassociais/base-de-dados/1149-pesquisa nacional-de-saneamento-basico. Acesso em 10 de novembro de 2019.

- Instituto Brasileiro de Geografia e Estatística (IBGE): Disponível em:

$<$ https://censo2010.ibge.gov.br/noticias-

censo.html?busca $=1$ \&id=1\&idnoticia $=2019 \& \mathrm{t}=$ indicadores-sociais-municipais-2010incidencia-pobreza-maior-municipios-porte-medio\&view=noticia >. Acesso em 05 mai. 2020.

BRASIL. Atlas de saneamento: 2011/IBGE. Diretoria de Geociências. Rio de Janeiro. Disponível em: -https://biblioteca.ibge.gov.br/index.php/bibliotecacatalogo?view=detalhes\&id=280933. 268p.: mapas. Acesso em 11 de novembro de 2019.

LEI № 9.433, DE 8 DE JANEIRO DE 1997, de 13 de março de 1990. Sistema Nacional de Informação sobre Saneamento (SNIS): Disponível em:<http://www.snis.gov.br/legislacao\#: :text=0\%20marco\%20regulat\%C3\%B3rio\% 20do\%20setor,domic\%C3\%ADlios\%20ocupados\%20ao\%20saneamento\%20b\%C3 \%A1sico.>. Acesso em 05 mai. 2020.

CALIARI, Rogério O; ALENCAR, Edgard; AMÂNCIO, Robson. Pedagogia da alternância e desenvolvimento local. Organizações Rurais \& Agroindustriais Revista de Administração da UFLA Universidade Federal de Lavras - UFLA Departamento de Administração e Economia, 2002.

CARVALHO, Thiago Morato de. Técnicas de medição de vazão por meios convencionais e não convencionais. Revista Brasileira de Geografia Física. RecifePE. V.1. №1, p.75-85, Maio/Agosto, 2008.

CHRISTOFOLETTI, A. Geomorfologia. São Paulo: Edgard Blücher. Ed da, 1980.

COSTA FILHO, A. G. Aplicação de sistemas alternativos para o tratamento de esgoto em áreas de mananciais em Santo André - Wetland. Disponível em:<http://www.semasa.sp.gov.br/Documentos/ASSEMAE/Trab_56.pdf>. Acesso em 25 ago. 2004.

DIÁRIO DAS LEIS. Portal de Legislação. Saneamento básico. Disponível em: 
http://www.diariodasleis.com.br/busca/exibelink.php?numlink=1-98-24-2007-01-0511445. Acesso em 20 de novembro de 2019.

DUARTE, Renato. Trabalhos para discussão: Dois modelos para a convivência do produtor rural com o ambiente do semi-árido nordestino. n. 109/2001. Março, 2001. Disponível em: <https://fundaj.emnuvens.com.br/PDF/article/view/924/645>. Acesso em 20 de outubro de 2018.

ECOCASA, Tecnologias ambientais. Fossa Negra. Fevereiro, 2016. Disponível em: < https://www.ecocasa.com.br/fossa-negra>. Acesso em 27 de novembro de 2019.

ESTEVES, F. A. Fundamentos de Limnologia. 2 ed. Rio de Janeiro: Interciência/FINEP, 1998. 602p.

IDAHO. Pollution Prevention. Department of Environmental Quality. 2019. Home page disponível em< https://www.deq.idaho.gov/pollution-prevention//> Acesso em 20 de set. de 2019.

Wastewater in Idaho. Department of Environmental Quality, 2019. Home page. Disponível em < https://www.deq.idaho.gov/water-quality/wastewater/> Acesso em 20 de set. de 2019.

JIA, H. F.; YAO, H. R.; TANG, Y.; Yu, S. L.; ZHEN, J. X.; LU, Y. W. (2013) Development of a multi-criteria index ranking system for urban storm water Best Management Practices (BMPs) selection. Environmental Monitoring and Assessment, Springer, v. 185, n. 9, p. 7915-7933.

LIMA, Rodrigo F. de S. (et. al). Potencialidades dos wetlands construídos empregados no pós-tratamento de esgotos: experiências brasileiras. 2016.

MAIA N. R. F. Água para o desenvolvimento sustentável. Revista água em revista, Belo Horizonte - MG V.5 no 9 p. 21-32, novembro, 1997.

MENDONÇA, Francisco; DANNI-OLIVEIRA, Inês Moresco. Climatologia: noções básicas e climas do Brasil. Oficina de textos, 2017.

NOGUEIRA, Ana Caroline Costa; IMPERADOR, Adriana Maria. DIAGNÓSTICO AMBIENTAL ATRAVÉS DO USO DA METODOLOGIA PARTICIPATIVA: ESTUDO DE CASO DA ALDEIA INDÍGENA XUCURU-KARIRI. Revista Eletrônica de Gestão e Tecnologias Ambientais, v. 4, n. 2, p. 207-219, 2016.

OLIJNYK, Débora Parcias et al. Sistemas de tratamento de esgoto por zona de raízes: análise comparativa de sistemas instalados no Estado de Santa Catarina. In: 24ํㅡㄹ Congresso Brasileiro de Engenharia Sanitária e Ambiental. 2007.

Organização Mundial de Saúde. OMS. Ambientes poluídos matam 1,7 milhão de crianças por ano, 2017. Disponível em: http://br.reuters.com/article/worldNews/idBRKBN16D1A3. Acesso em 22 novembro de 2019.

Informe sobre la salud en el mundo 2013: investigaciones para una cobertura sanitaria universal. Disponível https://www.who.int/whr/2013/report/es/. Acesso em 22 novembro de 2019. 
REBOUÇAS, Aldo da Cunha; BRAGA, Benedito; TUNDISI, José Galiza. ACADEMIA BRASILEIRA DE CIÊNCIAS (Org.). Águas doces no Brasil: capital ecológico, uso e conservação. 3. ed. rev. e map. São Paulo: Escrituras, 2006. 713p

RIBEIRO, Wagner Costa. Geografia política da água. São Paulo: Annablume, 2008. $162 p$.

RODRÍGUEZ, José Manuel Mateo; DA SILVA, Edson Vicente. Educação ambiental e desenvolvimento sustentável: problemática, tendências e desafios. Edições UFC, 2010.

SANTOS, I.; FILL, H.D.; SUGAI, M.R.V.; BUBA, H.; KISHI, R.T.; MARONE, E.; LAUTERT, L.F.C. Hidrometria Aplicada. Curitiba - Pr: Lactec, 2001. 372 p.

SANTOS, Jémison Mattos. Caracterização geoambiental do semi-árido. Texto técnico elaborado para documento da Secretaria de Recursos Hídricos da Bahia Programa Estadual de combate à desertificação e mitigação dos efeitos da seca. Salvador, 2008.

SANTOS, Jémison Mattos. Indicadores de desertificação no semiárido brasileiro: - caso de Campo Formoso - Bahia. Tese (Doutorado) - Programa de Pós Graduação em Geografia da Universidade Federal Fluminense-UFF, Niterói, 2016, 471p.

SANTOS, Milton. A natureza do espaço: técnica e tempo, razão e emoção. Edusp, 2002.

SOUZA, Yanna Julia Dantas; BEZERRA, Jardson Álvaro Freitas; ROLIM, Hozineide Oliveira; CUNHA, Jonathan de $S$. influência de fossas negras na contaminação de poços subterrâneos na comunidade vila nova, itaiçaba-ceará, (2012).

SALATI, E. Utilização de sistemas de wetlands construídas para tratamento de águas. Biológico, São Paulo, v. 65, n. 1/2, p. 113-116, 2003.

TRATA BRASIL. Estatísticas. Disponível em: http://www.tratabrasil.org.br/. Acesso em 12 novembro de 2019.

TRATA BRASIL. Manual do saneamento básico. Disponível em: http://www.tratabrasil.org.br/datafiles/uploads/estudos/pesquisa16/manual-imprensa.pdf. Acesso em 12 novembro de 2019.

- 0 que é saneamento? Disponível em: <http://www.tratabrasil.org.br/saneamento/o-que-e-saneamento>. Acesso em 22 abr. 2020.

UNICEF. Fundo das Nações Unidas para a Infância. Boas Práticas - Água e Saneamento nas Escolas do Semiárido. 2017 Caderno 06. Disponível em:< https://www.unicef.org/brazil/media/496/file >. Acesso em dezembro de 2019. 
UNICEF. United Nations Children's Fund. Sanitation. 2019. Disponível em https://data.unicef.org/topic/water-and-sanitation/sanitation/. Acesso em 23 novembro de 2019.

UN-WATER. Water, Sanitation and Hygiene. 2019. Disponível em: https://www.unwater.org/water-facts/water-sanitation-and-hygiene/. Acesso em 08 novembro de 2019.

VAN KAICK, T. S. Estação de tratamento de esgoto por meio de zona de raízes: uma proposta de tecnologia apropriada para saneamento básico no litoral do Paraná. 2002. 128 f. Dissertação (Mestrado em Tecnologia) - Universidade Tecnológica Federal do Paraná, Curitiba, 2002.

VELOSO, Henrique Pimenta et al. Sistema fitogeográfico. Manual técnico da vegetação brasileira, v. 1, 1992.

VON SPERLING, Marcos. Introdução à qualidade das águas e ao tratamento de esgotos. 3.ed. Belo Horizonte: Departamento de Engenharia Sanitária e Ambiental; Universidade Federal de Minas Gerais; 1996. p. 15 - 48.

World Health Organization. WHO. Inheriting the World: the Atlas of Children's Health and the Environment. 2017. Disponível em: file:///C:/Users/profe/AppData/Local/Packages/Microsoft.MicrosoftEdge_8wekyb3d8b bwe/TempState/Downloads/9789241511773-eng\%20(1).pdf. Acesso em 08 novembro de 2019.

WORLD HEALTH ORGANIZATION et al. Guidelines on sanitation and health. 2018. 